\title{
Maximal lactate steady state in Judo
}

\author{
Paulo Henrique Silva Marques de Azevedo \\ Tania Pithon-Curi \\ Alessandro Moura Zagatto \\ João Oliveira \\ Sérgio Perez
}

Ciências do Movimento Humano, Universidade Federal de São Paulo, Brazil

Corresponding author:

Paulo Henrique Silva Marques de Azevedo

Ciências do Movimento Humano,

Universidade Federal de São Paulo

136, Silva Jardim Street - Vila Mathias

11015-020 Santos, Brazil

E-mail: paulohazevedo@yahoo.com.br

\section{Summary}

Background: the purpose of this study was to verify the validity of respiratory compensation threshold (RCT) measured during a new single judo specific incremental test (JSIT) for aerobic demand evaluation. Methods: to test the validity of the new test, the JSIT was compared with Maximal Lactate Steady State (MLSS), which is the gold standard procedure for aerobic demand measuring. Eight well-trained male competitive judo players $(24.3 \pm 7.9$ years; height of $169.3 \pm$ $6.7 \mathrm{~cm}$; fat mass of $12.7 \pm 3.9 \%$ ) performed a maximal incremental specific test for judo to assess the RCT and performed on 30-minute MLSS test, where both tests were performed mimicking the UchiKomi drills. Results: the intensity at RCT measured on JSIT was not significantly different compared to MLSS $(p=0.40)$. In addition, it was observed high and significant correlation between MLSS and RCT $(r=0.90, p=0.002)$, as well as a high agreement. Conclusions: RCT measured during JSIT is a valid procedure to measure the aerobic demand, respecting the ecological validity of Judo.

KEYWORDS: ergometer, domain intensity, field test, metabolic demand, second ventilatory threshold.

\section{Introduction}

Numberless research articles in sports sciences are aimed to validate evaluation tests of physical capacity that are specific for the reality of the sportive activities $^{1-5}$, thus stimulating and monitoring the training effectiveness ${ }^{6}$. Within this perspective, there are few specific tests for judo ${ }^{7}$

The fact that judo is a complex modality with several body movements and metabolic interactions, makes it difficult to assess the aerobic performance specifically. The traditional incremental test on treadmill or cycle-ergometer exercises do not mimic the specific muscular demand and movement patterns performed during the judo match. Specific evaluation procedure and training regarding aerobic demand could improve performance in judo ${ }^{8}$. Furthermore, activities lasting more than 3 minutes are strongly influenced by aerobic metabolism ${ }^{9}$ and considering the overall judo match, the energy aerobic pathway has a relevant role in maintaining the high-intensity of efforts during the fight and for allowing for fast recovery after each effort periods, being the main energy system during the match ${ }^{10}$.

Until at the moment there is a lack in the science of validity specific tests to assess the aerobic demand in judo athletes. Moreover, the specific test for judo in the current literature cannot be used for intensity training prescription. Our hypothesis is the following: a) there will be no statistical difference between RCTrelated intensity and MLSS; b) there will be high agreement between the methods aimed at testing judo. Whether these hypotheses are confirmed, its open a new way for specific training because athlete could train with a specific and appropriate load, without the presence of another athlete (required for traditional UchiKomi). Therefore, the purpose of the present study was to verify the validity of respiratory compensation threshold (RCT) measured during a new single judo specific incremental test (JSIT) (i.e., performed mimicking the UchiKomi drills) for aerobic demand evaluation. Facing this purpose, the RCT measured on JSIT was compared with maximal lactate steady state (i.e., gold standard procedure for aerobic demand evaluating) that represent the upper limit of equilibrium between lactate production and removal ${ }^{11}$. The advantage to using JSIT is because this procedure needs only one single test, while MLSS requires 2 to 5 days. 


\section{Methods}

\section{Subjects}

Eight well-trained male judo athletes with a mean age of $24.2 \pm 6.4$ years old, mean height of $168.2 \pm 7.0$ $\mathrm{cm}$, and mean body mass of $65.4 \pm 13.2-\mathrm{kg}$ participated voluntarily in this study. Four judo athletes competed at national-level tournaments, whereas four others play state competitions. The mean time spent on training was $10.5 \pm 0.4$ hours a week. All participants of this investigation were textually and verbally informed about the possible intrinsic risks and benefits of the tests, signing a free informed consent. The study was approved by the research ethics committee of the Federal University of São Carlos, Brazil (Human Research Ethics Committee protocol number 257/2006) which followed the ethical standard of the Muscle, Ligament and Tendons Journal ${ }^{12}$.

\section{Study protocol}

All the subjects performed a specific incremental test (JSIT) and MLSS mimicking the Uchikomi using a cable crossover machine. The JSIT was performed until exhaustion. Next, constant workload was performed at intensities around Respiratory Compensation Threshold (RCT) for determination of Maximal Lactate Steady State (MLSS). The tests were conducted on the same period of the day, with a variation of 2 hours. The interval between test was 72 hours.

Warm-up exercises consisting of specific judo movements were performed for 5 minutes prior to each test. To minimize the learning effect, the judo athletes attended 5-minute UchiKomi sessions using a cable crossover machine for 4 non consecutive days ${ }^{13}$. The pace of Uchikomi was controlled through loud signs emitted by a metrometer ( $D^{\prime}$ Accord Metronome, freeware).

\section{Experimental procedures}

Specific actions during graded exercise and maximal lactate steady state in judo test

Both tests were developed so that uchikomi would be applied in association with ippon-seoi-nague technique using a cable crossover machine, with the adaptation of the kimono sleeves onto the equipment. The validity and reliability of UchiKomi use for anaerobic threshold determination has been demonstrated previously ${ }^{14}$. Initial load for JSIT was 1.9-kg, increasing $1.2-\mathrm{kg}$ every 3 minutes ${ }^{15}$. For MLSS test the load was around RCT determined during JSIT. UchiKomi movements had a frequency of one UchiKomi every 3 seconds ${ }^{16}$. The test was finished when the subject stopped the movement voluntarily due to exhaustion, when the pre-determined frequency was not kept during 3 consecutive Uchikomi, or when Uchikomi was performed out of the technical pattern. At the end of each stage, there was a 30-second interval for load increment during JSIT, or blood collection during MLSS test.

Graded exercise test for respiratory compensation threshold determination in Judo

Measurements of $\mathrm{VO}_{2}, \mathrm{VCO}_{2}$ and ventilation were carried out throughout each test using a telemetry system (K4b2, Cosmed, Rome, Italy). Expired gases were measured breath-by-breath and the results were averaged every 15 seconds. Before each test, the system for $\mathrm{O}_{2}$ analysis was calibrated using ambient air and a gas of known $\mathrm{O}_{2}$ and $\mathrm{CO}_{2}$ concentration according to the manufacturer's instructions ( $\mathrm{K} 4 \mathrm{~b}^{2}$ instruction manual) and subjects remain standing during 5 minutes for data acquisition and normalization. The turbine flowmeter of the $\mathrm{K} 4 \mathrm{~b}^{2}$ was calibrated using a 3-L syringe. The RCT was determined by means of three ventilatory parameters: 1) second loss in ventilatory linearity; 2) increase of representative curve corresponding to ventilatory equivalent of $\left.\mathrm{CO}_{2}\left(\mathrm{VE} / \mathrm{VCO}_{2}\right) ; 3\right) \mathrm{de}-$ crease in the fraction of expired $\mathrm{CO}_{2}\left(\% \mathrm{FeCO}_{2}\right)^{17}$. Two experienced scientists evaluated each graph, and in the case of discrepancies, the mean of the identified points was used.

\section{Maximal lactate steady state}

A constant-load test was carried out during 30 minutes $^{11}$. A minimum of 48 hours and a maximum of 96 hours of intervals were allowed after JSIT as well as between the tests for MLSS determination. This test was performed at an intensity of $1.2-\mathrm{kg}$ below the $\mathrm{RCT}$, at an intensity corresponding to RCT, and 1.2$\mathrm{kg}$ above the RCT intensity. MLSS was considered as being the greatest intensity in which blood lactate concentration did not increase more than 1-mmol. $\mathrm{L}^{-1}$ between 10 and 30 minutes ${ }^{11}$.

\section{Blood collection and analysis}

Blood sample collection was carried out by puncture with disposable lancet perforating ear lobe. Heparised capillaries were used for containing $25-\mu \mathrm{L}$ of arterial blood, which were then put in Eppendorf tubes containing $50-\mu \mathrm{L}$ of $1 \%$ sodium fluoride. All samples were stored in the freezer for adequate conservation and further analysis. Blood lactate concentrations were measured by an electro-enzymatic lactate analyzer (Model YSI 1500 Sports - Yellow Springs Instruments, Ohio, USA). The values of lactate were expressed in mmol. $\mathrm{L}^{-1}$.

\section{Statistical analysis}

Data are presented as mean $\pm S D$. The difference between the intensity related to RCT and MLSS was analyzed with a paired $t$-test. It was also applied the 
Shapiro-Wilk test for assessing the normality data. The relationships between RCT and MLSS were determined by the Pearson's correlation coefficient. Coefficient of variation was calculated as follows: $C V=(S D / m e a n) \times 100$. The significant level was set at $p \leq 0.05$. Moreover, error and limits of agreement between methods ${ }^{11}$ were calculated, considering MLSS as gold standard. The minimal sample power required for this study was eleven.

\section{Results}

The load, percentage of maximum, blood lactate concentration, heart rate and $\mathrm{VO}_{2}$ at RCT and MLSS and their coefficient of variations were presented in Table 1. Uchikomi absolute and percentage load at RCT was not significantly different compared to MLSS ( $p$ $>0.05)$. These values were significantly correlate $\left(r=0.90 ; R^{2}=0.80 ; p=0.002\right)$ and showed high agreement between MLSS and RCT (Fig. 1). Low bias and relatively narrow limits of agreement [Bias $( \pm 95 \%$ confidence interval)] for MLSS and RCT [-0.3 (1.04) $\mathrm{kg}$ ] was observed ${ }^{18}$. The coefficient of variations was demonstrated in Table 1.

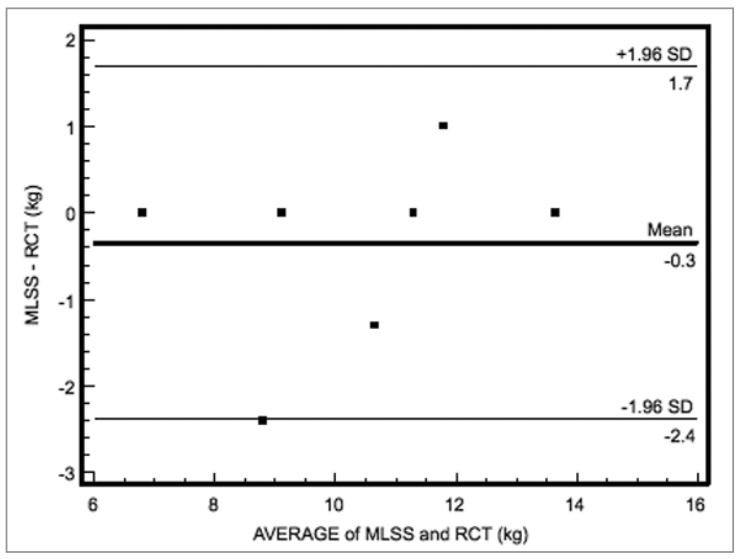

Figure 1. Bland-Altman plots showing the bias and limits of agreement in comparison of MLSS and RCT. The solid horizontal line represents the bias between the two measures. The dashed lines represent the $95 \%$ limits of agreement between the two variables.

\section{Discussion}

The main finding was that RCT may predict the MLSS in a specific judo test by means of the non-invasive methodology. Although considered an effective test, the MLSS identification needs two to five constant work loads exercise tests of up 20 to 30 -min duration. Therefore, a single and noninvasive test for MLSS prediction becomes interesting for athlete evaluation and training prescription.

The traditional laboratory tests using a treadmill or cycle-ergometer for determination of sub-maximum (RCT) parameters seem not to be able to discriminate elite athletes from non-elite one ${ }^{19}$. In an attempt to fulfill this gap, the test being suggested here opens a good perspective for evaluating the judo athlete's aerobic capacity. Comparison of the individual load test results between RCT and MLSS can be observed in Figure 1. Four subjects had the same intensity for either RCT or MLSS, with low estimation error (bias) indicating that such parameters are interchangeable. Lactate concentration at RCT and MLSS were similar to reported in other studies with different sports and methods 20,21 . The $\mathrm{VO}_{2}$ max determined by incremental test was similar to reported in literature with specific and non-specific methods ${ }^{14,22,23}$. Therefore, JIST will serve as an intensity parameter for training and evaluation purposes.

The percentage values for RCT and MLSS at JIST, in relation to peak load, were found to be similar to that reported in the literature on tests based on a treadmill and cycle-ergometer $20,24,25$. It was observed good correlation and agreement between MLSS and RCT. Because this similarity found we suggest that RCT can be used instead of MLSS to determine the athlete's evolution and specific intensity of training for judo.

The development of a specific procedure for judo is complex because several variables are needed for a good performance during the combat ${ }^{26}$. In the present study, we have used only "ippon-seoi-nague". It should be emphasized that this modality also involves another type of throwing movements (e.g. uchi-mata, o-soto-gari, among others) that are important and largely employed for sports performance. However, ippon-seoi-nague is a technique similar to morote-seoinague, that depends more the aerobic energy yield during its execution ${ }^{27}$. These facts, largely employ-

Table 1. The absolute and percentage of peak load for RCT and MLSS.

\begin{tabular}{|c|c|c|c|c|c|}
\hline & $\begin{array}{l}\text { Absolute Load } \\
\text { (Kg) }\end{array}$ & $\begin{array}{l}\text { Percentual of Peak } \\
\text { load (\%) }\end{array}$ & $\begin{array}{l}\text { Heart Rate } \\
\text { (bpm) }\end{array}$ & $\begin{array}{l}{\left[\mathrm{Lac}^{-}\right]} \\
\left(\mathrm{mmol}^{\left.-\mathrm{L}^{-1}\right)}\right.\end{array}$ & $\begin{array}{l}\mathrm{VO}_{2} \\
\left(\mathrm{ml} \mathrm{kg}^{-1} \cdot \mathrm{min}^{-1}\right)\end{array}$ \\
\hline $\mathrm{RCT}$ & $\begin{array}{l}10.3 \pm 1.9 \\
(8.6-12.0)\end{array}$ & $\begin{array}{l}82.6 \pm 2.8 \\
(80.1-5.1)\end{array}$ & $\begin{array}{l}169.9 \pm 3.5 \\
(160.6-77.1)\end{array}$ & $\begin{array}{l}2.9 \pm 0.8 \\
(2.0-3.6)\end{array}$ & $\begin{array}{l}38.4 \pm 4.9 \\
(34.0-2.8)\end{array}$ \\
\hline C.V. & 18.4 & 3.4 & 2.1 & 27.6 & 12.8 \\
\hline MLSS & $\begin{array}{l}10.0 \pm 2.3 \\
(8.0-11.9)\end{array}$ & $\begin{array}{l}79.9 \pm 8.5 \\
(72.3-7.4)\end{array}$ & $\begin{array}{l}166.6 \pm 6.1 \\
(152.1-81.0)\end{array}$ & $\begin{array}{l}3.1 \pm 0.8 \\
(2.4-3.9)\end{array}$ & \\
\hline C.V. & 23.0 & 10.6 & 3.7 & 25.8 & - \\
\hline$P$-value & 0.388 & 0.378 & 0.751 & 0.608 & - \\
\hline Effect size & 0.14 & 0.48 & 0.69 & 0.31 & - \\
\hline
\end{tabular}


ment and high aerobic demand for ippon-seoi-nague techniques, strengthens the method proposed here. One of the limitations during the judo fights is the handgrip fatigue 28 . Improving specifically the handgrip endurance can contribute to optimal performance ${ }^{28}$. These muscles represent a crucial factor that limits the tests being conducted, according to a report by the subjects. A good simulation was observed in one of the limiting factors that occur during a real combat. The stressful components of competition may temporarily impair an athlete's performance during a subsequent combat. So, a specific evaluation procedure and training regarding endurance capacity could improve performance in judo between and within combats.

Due to predominantly aerobic metabolism during judo match ${ }^{10}$, it is clearly the need for determining the intensity of exercise to adequately prescript the specific aerobic training. It is recommended that physical exercises during judo training use upper and lower limbs jointly with an intensity associated with lactate threshold ${ }^{29}$, 30. Therefore, the JIST can contribute to making the kinetic chain movement to be closer to the reality. This specificity of evaluation and training could induce to a better performance and adaptation of the judo athlete in keeping intense physical efforts without becoming exhausted 29,30 , thus yielding less lactate concentration and faster re-synthesis of phosphate creatine ${ }^{8}$.

Here we used the second ventilatory threshold for estimation of MLSS. For judo, two studies were aimed at determining the intensity associated with MLSS by using the minimum lactate concept ${ }^{16}$ and individual anaerobic threshold ${ }^{14}$. The lactate minimum test has been found to be a good way for predicting such intensity $^{31}$. Both methods represent the upper limit of effort intensity in which lactate appearance is in dynamic balance with its removal from the blood ${ }^{11,20}$. It has been suggested that training at MLSS intensity is adequate approach to improve the aerobic power and capacity ${ }^{32}$. Possibly the limitation of this study is the number of subjects. The minimal sample power required for this study was eleven. However, all data were considered with normal distribution. Other procedures like testretest, verify if JSIT is able to discriminate level of performance in judo players. The strengths of this study are a novel strategy to determine in a specific way the aerobic capacity for judo athletes, and the methodology reported here could be applied as judo evaluation and load training prescription.

In conclusion, JSIT was cross-validated to specifically estimate MLSS for sporting purposes. Therefore, the JSIT can be used to evaluate the aerobic conditioning of judo practitioners and for prescribing adequate intensity training.

\section{References}

1. Azevedo PHSM, Drigo AJ, Oliveira PR, Carvalho MCGA, Sabino Jr M. A systematization of the training period of the judo athlete Mario Sabino: a case study on the year 2003. Rev Bras Cienc Esporte. 2004;26(1):73-86.

2. Blais $L$, Trilles $F$, Lacouture P. Validation of a specific machine to the strength training of judokas. J Strength Cond Res. 2007;21(2):409-412.

3. Girard O, Chevalier R, Leveque F, Micallef JP, Millet GP. Specific incremental field test for aerobic fitness in tennis. $\mathrm{Br} J$ Sports Med. 2006;40(9):791-796.

4. Micklewright D, Papapdopoulou E. A new squash specific incremental field test. Int J Sports Med. 2008;29(9):758-763.

5. Zagatto AM, Beck WR, Gobatto CA. Validity of the Running Anaerobic Sprint Test for Assessing Anaerobic Power and Predicting Short-Distance Performances. J Strength Cond Res. 2009;23(6):1820-1827.

6. Bishop D. The validity of physiological variables to assess training intensity in kayak athletes. Int J Sports Med. 2004; 25(1):68-72.

7. Carvalho MCGA. Testes motores específicos para o judô, necessidade frente à uma limitada quantidade. Kinesis. 2000;23:1-19.

8. Drigo AJ, Amorim AR, Martins CJ, Molina R. Demanda metabólica em lutas de projeção e de solo no judô: estudo pela lactato sanguíneo. Motriz. 1996;2(2):80-86.

9. Green S. Measurement of anaerobic work capacities in humans. Sports Med. 1995;19(1):32-42.

10. Artioli GG, Bertuzzi RC, Roschel H, Mendes SH, Lancha AH, Jr., Franchini E. Determining the contribution of the energy systems during exercise. J Vis Exp. 2012;20:(61), pii: 3413.

11. Beneke R. Maximal lactate steady state concentration (MLSS): experimental and modelling approaches. Eur J Appl Physiol. 2003;88(4-5):361-369.

12. Padulo J, Oliva F, Frizziero A, Maffulli N. Muscles, Ligaments and Tendons Journal. Basic principles and recommendations in clinical and field science research. MLTJ. 2013;4:250-252.

13. Papoti M, Vitório R, Araújo GG, et al. Determination of force corresponding to maximal lactate steady state in tethered swimming. Int J Exerc Sci. 2009;2(4):269-279.

14. Santos L, Gonzalez V, Iscar M, et al. A new individual and specific test to determine the aerobic-anaerobic transition zone (Santos Test) in competitive judokas. J Strength Cond Res. 2010;24(9):2419-2428.

15. Bentley DJ, Newell J, Bishop D. Incremental exercise test design and analysis: implications for performance diagnostics in endurance athletes. Sports Med. 2007;37(7):575-586.

16. Azevedo PHSM, Drigo AJ, Carvalho MCGA, et al. Determination of judo endurance performance using the Uchi - Komi technique and an adapted lactate minimum test. J Sports Sci \& Med. 2007;6(CSSI-2):10-14.

17. Bhambhani $Y$, Singh $M$. Ventilatory thresholds during a graded exercise test. Respiration. 1985;47(2):120-128.

18. Bland JM, Altman DG. Statistical methods for assessing agreement between two methods of clinical measurement. Lancet. 1986;8;1(8476):307-310.

19. Taylor AW, Brassard L. A physiological profile of the Canadian Judo Team. J Sports Med. 1981;21:160-164.

20. Beneke R, Hutler M, Leithauser RM. Maximal lactate-steadystate independent of performance. Med Sci Sports Exerc. 2000;32(6):1135-1139.

21. Beneke R, Leithauser RM, Hutler M. Dependence of the maximal lactate steady state on the motor pattern of exercise. $\mathrm{Br} J$ Sports Med. 2001;35(3):192-196.

22. Franchini E, Brito CJ, Fukuda DH, Artioli GG. The Physiology of Judo-Specific Training Modalities. J Strength Cond Res. 2014;28(5):1474-1481.

23. Franchini E, Panissa VL, Julio UF. Physiological and performance responses to intermittent Uchi-komi in Judo. J Strength Cond Res. 2013;27(4):1147-1155.

24. Dekerle J, Baron B, Dupont L, Vanvelcenaher J, Pelayo P. Maximal lactate steady state, respiratory compensation threshold and critical power. Eur J Appl Physiol. 2003;89(34):281-288. 
25. Harnish CR, Swensen TC, Pate RR. Methods for estimating the maximal lactate steady state in trained cyclists. Med Sci Sports Exerc. 2001;33(6):1052-1055

26. Blais $L$, Trilles $F$. The progress achieved by judokas after strength training with a judo-specific machine. J Sports Sci \& Med. 2006;5(CSSI):132-135.

27. Franchini E, Bertuzzi RCM, Degaki E, Mello FC, Fiebig E, Silva WFFL. Energy expenditure in different judo throwing techniques. Bio-mechanics and sports engineering. 2008;II:55-60.

28. Bonitch-Gongora JG, Bonitch-Dominguez JG, Padial P, Feriche $B$. The effect of lactate concentration on the handgrip strength during judo bouts. J Strength Cond Res. 2012; 26(7):1863-1871
29. Thomas SG, Cox MH, LeGal YM, Verde TJ, Smith HK. Physiological profiles of the Canadian National Judo Team. Can J Sport Sci. 1989;14(3):142-147.

30. Tumilty D, Hahn A, Telford RD. A physiological profile of welltrained male judo players, with proposals for training. Excel. 1986;2(4):12-14.

31. Jones AM, Doust JH. The validity of the lactate minimum test for determination of the maximal lactate steady state. Med Sci Sports Exerc. 1998;30(8):1304-1313.

32. Philp A, Macdonald AL, Carter H, Watt PW, Pringle JS. Maximal lactate steady state as a training stimulus. Int J Sports Med. 2008;29(6):475-479. 